\title{
Mixed type Castleman's disease with renal amyloidosis: Case report
}

\author{
Emre Erdem $^{\text {**, Dilek Erdem }}{ }^{\mathrm{a}}$, Nurol Arık ${ }^{\mathrm{a}}$, İdris Yücel ${ }^{\mathrm{b}}$ \\ ${ }^{a}$ Department of Nephrology, Medical Faculty, Ondokuz Mayls University, Samsun, Turkey \\ ${ }^{b}$ Department of Medical Oncology, Medical Faculty, Ondokuz Mayı University, Samsun, Turkey
}

ARTICLE INFO ABSTRACT

\section{Article History}

Received $\quad 10 / 04 / 2011$

Accepted $14 / 05 / 2011$

\section{* Correspondence to:}

Emre Erdem

Department of Nephrology,

Medical Faculty,

Ondokuz Mayıs University,

Samsun, Turkey

e-mail: emredlk@yahoo.com
Castleman's disease is a lymphoproliferative disorder and accompanying renal amyloidosis has been rarely described. We report a case of Castleman's disease with nephrotic syndrome secondary to amyloidosis. A 28 year old woman who has been followed by our unit with two years of Castleman's disease was referred to our clinic with newly diagnosed proteinuria and renal failure. Renal biopsy showed amyloid deposit and the patient was treated with colchicine. The patient did not respond to colchicine therapy and the renal failure rapidly progressed.

J. Exp. Clin. Med., 2013; 30:67-68

\section{Keywords:}

Amyloidosis

Castleman's disease

Colchicine

Proteinuria

Renal biopsy

Renal failure

\section{Introduction}

Castleman's disease (CD) was first described in 1956 as a benign lymphoproliferative disease (Castleman et al., 1956). Two main histological pattern of $C D$ were described: The hyaline vascular type and plasma cell type. Mixed type has also been described. The hyaline vascular type accounts for $80-90 \%$ of all cases. The plasma cell type constitutes remaining $10-20 \%$ of cases. The hyalin vascular type is usually unicentric and clinically presented as a mediastinal or mesenteric mass. It usually produces only a mass effect. The plasma cell type is multicentric in the majority of cases and clinically presented with systemic manifestations such as fever, peripheral lymphadenopathy, splenomegaly, policlonal hypergammaglobulinemia, anemia and thrombocytopenia. Symptoms mimic an inflammatory illness (Frizzera et al.,1985; Androulaki et al., 2007).

Renal complications from CD are infrequent. These included; renal amyloidosis, membranous glomerulonephritis, membranoproliferative glomerulonephritis, cresentic glomerulonefritis, interstitial nephritis and thrombotic microan- giopathy (Suneja et al., 2009). We report a case of CD with renal amyloidosis and nephrotic syndrome.

\section{Case}

A 26 year old woman was refered to our hospital in February 2007 with fatigue and abdominal pain. Physical examination was normal. Laboratory findings were as follows: Hemoglobin:11.7 g/dl, blood urea nitrogen: $4.7 \mathrm{mg} / \mathrm{dl}$, creatinin: $0.39 \mathrm{mg} / \mathrm{dl}$, albumin: $3.0 \mathrm{~g} / \mathrm{dl}$, alkaline phosphatase (ALP): $1148 \mathrm{U} / \mathrm{L}$, gammaglutamyltransferase (GGT): 78 $\mathrm{U} / \mathrm{L}$, erythrocyte sedimentation rate (ESR): $88 \mathrm{~mm} / \mathrm{h}$, c-reactive protein (CRP): $97 \mathrm{mg} / \mathrm{L}$. Serum electrolytes, alaninaminotransferase (ALT), aspartataminotransferase (AST), bilirubins were normal. An abdominopelvic and thoracic computed tomography (CT) were performed. Thoracic CT was normal. Abdominopelvic CT showed hepatosplenomegaly, $7 \mathrm{~cm}$ solid mass in retrocaval area and another $4 \mathrm{~cm}$ solid mass, which was located near porta hepatis. A laparotomy was performed and excision biopsy showed mixed type CD (hyaline vascular and plasma cell). Mixed type multicentric CD was diagnosed. 
Six cycles of chemotherapy with cyclophosphamid, vincristine, adriamycin, prednisolon were administered from July 2007 to November 2007. Abdominopelvic CT was performed after six cycles of chemotherapy which revealed a reduction in size of masses. The patient was followed up until February 2009 without treatment. In February 2009 her physical examination was normal, laboratory findings were as follows: Creatinin $0.3 \mathrm{mg} / \mathrm{dl}$, albumin: $2.4 \mathrm{~g} / \mathrm{dl}$, ALP: $2379 \mathrm{U} / \mathrm{L}$, GGT: $255 \mathrm{U} / \mathrm{L}$. ALT, AST and bilirubins were normal. Abdominopelvic CT showed progression. After February 2009; the patient did not come to clinic control for approximately a year. One year later, she was admitted to hospital because of nausea, fatigue and edema in October 2010. Physical examination was normal apart from +1 pretibial edema. Results of laboratory findings were as follows: Hemoglobin: $9 \mathrm{~g} / \mathrm{dl}$, creatinin: $2.34 \mathrm{mg} / \mathrm{dl}$, albumin: $1.8 \mathrm{~g} / \mathrm{dl}$, ALP $3249 \mathrm{U} / \mathrm{L}$, GGT $349 \mathrm{U} / \mathrm{L}$, urinary spot protein $(\mathrm{mg} / \mathrm{dl}) /$ creatinin $(\mathrm{mg} / \mathrm{dl})$ ratio: 20, ESR: $110 \mathrm{~mm} / \mathrm{h}, \mathrm{CRP}: 42 \mathrm{mg} / \mathrm{L}$. Both renal size were normal in abdominal ultrasonography. The patient underwent renal biopsy because of nephrotic syndrome and the biopsy revealed marked amyloid deposit. Colchicine therapy was initiated. Three months later the patient's laboratory findings were repeated and results were as follows: Hemoglobin: 11.6 $\mathrm{g} / \mathrm{dl}$, creatinin: $4.4 \mathrm{mg} / \mathrm{dl}$, albumin $2.1 \mathrm{~g} / \mathrm{dl}$, urinary spot protein $(\mathrm{mg} / \mathrm{dl}) /$ creatinin $(\mathrm{mg} / \mathrm{dl})$ ratio: 24 . The patient did not respond to colchicine and was started hemodialysis therapy.

\section{Discussion}

Systemic amyloidosis is a rare complication of CD. Secondary amyloidosis (AA type) is associated with recurrent infec- tions and chronic inflammatory disease. In patients with CD, $\mathrm{B}$ cells in germinal centers of hyperplastic lymph nodes continuously produce excessive IL-6, which is one of the major stimulants of acute phase protein synthesis by hepatocytes. Serum amyloid A (SAA) protein is a precursor of amyloid A protein. The overproduction of SAA due to IL-6 stimulation of hepatocytes can lead to AA amyloidosis (Androulaki et al., 2007; Morita-Hoshi et al., 2008).

In a Medline search so far 45 cases of $C D$ with secondary amyloidosis had been diagnosed. In the review by MoritaHoshi et al. (2008) most cases with amyloidosis had plasma cell type $\mathrm{CD}$, second frequently mixed type CD. $70 \%$ of patients had unicentric CD. Almost all cases had AA type amyloidosis. Only two cases with AL type amyloidosis were reported (Morita-Hoshi et al., 2008). Our case was a multicentric mixed type CD.

The ideal form of treatment in $\mathrm{CD}$ is controversial. Tumor resection, systemic chemotherapy, anti-CD20 antibody and anti IL- 6 receptor antibody have been attempted (Androulaki et al., 2007; Morita-Hoshi et al., 2008). In our case; there was no response in laboratory or clinical findings after systemic chemotherapy. The patient also did not respond to colchicine therapy. Renal failure rapidly progressed.

In conclusion, mixed type $\mathrm{CD}$ tends to be multicentric and aggresive. Systemic amyloidosis due to CD could develop in a relatively short time. The amyloid deposition seems to be related to the tumor and does not tend to respond to colchine therapy. Patients with CD need to be monitored for renal function and proteinuria. If proteinuria is detected, amyloidosis should be kept in mind.

\section{REFERENCES}

Androulaki, A., Giaslakiotis, K., Giakoumi, X., Aessopos, A., Lazaris, A.C., 2007. Localized Castleman's disease associated with systemic AA amyloidosis. Regression of amyloid deposits after tumor removal. Ann. Hematol. 86, 55-57.

Castleman, B., Iverson, L., Menendez, V.P., 1956. Localized mediastinal lymph node hyperplasia resembling thymoma. Cancer. 9, 822-830.

Frizzera, G., Peterson, B.A., Bayrd, E.D., Goldman, A., 1985. A systemic lymphoproliferative disorder with morphologic features of Castleman's disaese: Clinical findings and clinicopathologic correlations in 15 patients. J. Clin. Oncol. 3, 1202-1216.

Morita-Hoshi, Y., Tohda, S., Miura, O., Nara, N., 2008. An autopsy case of multisentric Castleman's diasease associated with interstitial nephritis and secondary AA amyloidosis. Int. J. Hematol. 87, 69-74.

Suneja, S., Chidambaram, M., Herzenberg, A.M., Bargman, J.M., 2009. Kidney involvement in multisentric castleman disease. Am. J. Kidney. Dis. $53,550-554$. 